\title{
TEORIA E ARQUEOLOGIA ATRAVÉS DE EVENTOS: A ESCOLA AMERICANA E A ESCOLA FRANCESA
}

\author{
Tatiana de Lima Pedrosa Santos ${ }^{1}$
}

\section{RESUMO}

O artigo trata de uma abordagem sob a perspectiva discursiva de duas Escolas Teóricas e Metodológicas da Arqueologia Brasileira. Dando destaque a dois expoentes na Arqueologia Brasileira: Annette Laming-Emperaire e Betty Jane Meggers. A análise exposta tem como base a teoria da interpretação de Paul Ricoeur e investiga como se deu a transformação dessas duas arqueólogas em Eventos na Arqueologia Brasileira: a Escola Francesa e a Escola Americana. Partindo da dinâmica tripartite da relação texto- contexto- leitor, a discursividade aqui referendada surge da dialética Evento - Significação, dado a partir do pioneirismo dessas pesquisadoras.

Palavras-chave: Escolas arqueológicas, Meggers, Emperaire, Teoria, Arqueologia.

\section{ABSTRACT}

The article deals with an approach under the discursive perspective two schools Theoretical and Methodological the Brazilian Archaeology. Highlighting two exponents in the Brazilian Archaeology: Annette Laming - Emperaire and Betty Jane Meggers. The above analysis is based on the theory of interpretation of Paul Ricoeur and investigates how was the transformation of these two archeologists Events in Brazilian Archaeology: the French School and the American School. Starting from the dynamic of the tripartite text- contextreader relationship, the discourse referenced here comes the dialectic Event - Significance, given from the firsts of these researchers.

Keywords: archaeological schools, Meggers, Emperaire, Theory, Archaeology .

\section{RESUMEN}

El artículo trata de un enfoque bajo la perspectiva discursiva de dos escuelas teóricas y metodológicas de la Arqueología brasileña. Destacando dos exponentes de la arqueología brasileña: Annette Laming-emperaire y Betty Jane Meggers. El análisis anterior se basa en la teoría de la interpretación de Paul Ricoeur e investiga cómo fue la transformación de estos dos arqueólogos en Eventos en la Arqueología brasileña: la escuela francesa y la Escuela Americana. A partir de la dinámica tripartita de la relación texto-contexto-lector, el discurso que se hace referencia aquí viene del Evento dialéctica - Importancia, dado a partir de estos investigadores pioneros.

Palabras clave: escuelas arqueológicas, Meggers, Emperaire, Teoría, Arqueología.

\footnotetext{
1 Dra. Tatiana de Lima Pedrosa Santos. Professora do curso de Arqueologia da Universidade Estadual do Amazonas e responsável pelo Laboratório Alfredo Mendonça. Rua 3, casa 12, Condomínio Parque Aripuanã, Manaus- Am. (92) 994221009. tatixpedrosa@yahoo.com.br
} 


\section{Introdução}

Quando se trata de arqueologia é comum fazermos referências a trabalhos cuja pertinência está mais voltada ao trabalho com a cultura material. Ou precisamente, com os dados que seriam extraídos ao manusear-se uma determinada cultura material. Os questionamentos comuns, e tradicionalmente vistos e revistos pela arqueologia, seriam subtraídos das escalas, datações e tipos de classificação de um trabalho de campo. Por sua vez, estes poderiam associar-se a questionamentos mais amplos. Preocupados com as transições de um período ao outro, ou as escalas evolutivas de uma determinada sociedade, ou ainda com a identificação de uma sequência linear ou não.

O certo é que todo esse trabalho passa, de alguma forma, pelo processo da textualização que inexoravelmente vem representar um determinado tipo de história cujos eventos, numa perspectiva cronológica, possuem um começo, meio e fim.

A própria "crise de representação" do começo do século levou as Ciências Humanas a repensarem suas formas de retórica enquanto poder e distanciamento. Muitos consideram que essa "reforma" começou no movimento Renascentista do século XIX terminando nas discussões pós-modernas da "análise do discurso". O certo é que a maioria das Ciências Humanas buscou discutir mudanças a partir de suas esferas epistemológicas, inclusive para se ratificar como ciência (LIMA, 1990; MORIN, 2003).

Por sua vez, os debates da atualidade, ou pós-modernidade, afetaram a maneira como se faz História e Arqueologia. Essas discussões foram geradas e substanciadas nos embates filosóficos a partir da década de 60 e depois paulatinamente tomou diversas ramificações e características particulares quando nas disciplinas especificas (LIMA, 1990; MORIN, 2003).

Essas novas correntes propõem rever as tradições rígidas ligadas ao Empiricismo e ao Positivismo. Propondo uma abertura às críticas ao "sagrado e intocável", levando as discussões cientificas a questões centrais como a própria ideia que se tem de passado, a produção objetiva e subjetiva de conhecimento, e a revisão de determinadas ideologias e intencionalidades na prática cientifica (TILLEY 1999; HODDER 2000; PIRIE 2004).

O interesse é surfar por entre essas relações teóricas características de um pensamento moderno ou pós-moderno. Não a maneira generalista e indeterminada, mas o alvo perpassa pelo debate de forma particularizada na relação entre construção do passado e História, acercando-se das discussões que essas posturas assumem na Arqueologia e o "modo" com que o passado é "descoberto ou inventado" na dinâmica dessas disciplinas (PEDROSA, 2008). 
O debate intensifica-se ao perceber que essas posturas na sua condição de relatos históricos ganham peso extra ao assumir o rótulo de representações legítimas e emblemáticas de um passado que foi construído. Nessa condição, essas representações devem ser vistas não só nas suas estratégias textuais (sua construção interna), mas também nas suas relações sociais (sua construção externa) de forma a perceber as imagens que foram construídas e sedimentadas a partir de então (PIRIE, 2004).

A intenção é discutir o impacto de pensamentos, críticas e paradigmas em determinadas práticas e que "emblemas" estes pensamentos assumiram ao longo do tempo e de um determinado contexto. A questão que impulsiona as problemáticas é tentar perceber como uma determinada "lógica" através de um determinado discurso consegue persuadir e seduzir ao ponto de corresponder à determinada afirmação que se torna preponderante e expressão de um mundo.

\section{“QUEM CONTA UM CONTO, AUMENTA UM PONTO.”}

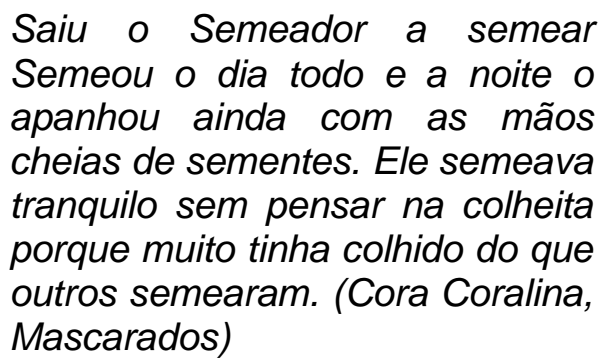

Trataremos de certas rotulações que determinados trabalhos assumiram ao longo do tempo, criando imagens ou ideias que se perpetuam. Interpretação cujo poder é tão forte que $z$ acaba abafando outras interpretações possíveis. Essas imagens que se tem como tão real e verdadeira são feitas, muitas vezes, a partir de recortes que ao final dão conta de um mosaico que traduz pretensamente esse "real" como um todo.

Trata-se da investigação de uma determinada estrutura embasada a partir de textos, ou de frases verbalizadas que indicam para um determinado sentido e reflexão. Esses determinados pensamentos foram enquadrados e engendrados ao longo do tempo nas práticas científicas arqueológicas que as assumiram e as naturalizaram. Porém, isso não significa dizer que estas fossem as posturas iniciais dos autores em questão. Só que em larga medida, se tornaram não só pensamentos, mas estratégias hegemônicas, contínuas, e muitas vezes inquestionáveis. 
Esses pensamentos e suas práticas são estabelecidos, através de paradigmas, no momento em que conseguimos estabelecer um conjunto de significados estáveis e principalmente de referências externas a esse conjunto.

Se entendermos como paradigmas (Khun) um conjunto de postulados teóricos, explicita ou implicitamente aceitos pelos investigadores de uma dada época (ou por uma fração significativa deles) postulados esses que perfilam um "campo mental" dentro do qual cabem as perguntas que os autores fazem aos dados e as respostas que destes esperam obter (na verdade os próprios "dados" resultam já de uma filtragem possibilitada pelo paradigma) - então a história da Arqueologia, como ade qualquer ciência, pode encarar-se como uma sucessão de paradigmas, cada um deles iniciado por uma "ruptura epistemológica" que, processada de início por uma "minoria inovadora", se vai pouco a pouco diluindo no cotidiano da "pesquisa corrente". Evidentemente, as coisas em geral não são assim tão simples (OLIVEIRA JORGE, 1987: 61).

Nesse ponto é importante dar atenção às condições que regem a produção e transmissão de significados. Quais os motivos que levam alguns significados surgirem, persistirem e repentinamente entrarem em colapso em determinados momentos e situações acadêmicas e socioculturais.

Talvez seja dessa forma que possamos encarar determinadas figuras ou expoentes que foram na História da Arqueologia importantes nessa dinâmica de significação através do tempo.

O fenômeno central é produzido ao nível do discurso, em que a problemática é analisada a partir da dinâmica triparte entre texto, contexto e leitura. Em que se toma como fonte e matriz geradora de significados a vida e obra de duas autoras e arqueólogas, Betty Jane Meggers (1921-2012) e Annette Laming-Emperaire (1917-1977).

O fenômeno é a relação ou associação das duas arqueólogas a Escolas Arqueológicas citadas e evidenciadas a partir da historiografia arqueológica, ora como não existentes, ora na sua prerrogativa de correntes ou linhas de pensamento arqueológico. Convencionou-se associar o nome de Betty J. Meggers à Escola Americana, e Annette L. Emperaire à Escola Francesa. Numa tentativa de explicação do que seriam as tais Escolas, se recorre à metáfora em que, a Escola Americana é Meggers, e a Escola Francesa é Emperaire.

Eis que se surgem algumas questões: Por que seus nomes são relacionados ou referenciados a Escolas teóricas que supostamente existiriam na Arqueologia Brasileira? Como se dá a associação das duas arqueólogas, respectivamente, à Escola Americana e à Escola Francesa? Qual seria a mensagem particular e única transcorrida através dos textos 
nos quais seus leitores as reconheceriam como "Escolas"? O que são essas Escolas teóricas? Elas, de fato, existem?

Chama-se atenção para o fato de que uma parcela desse enredo parte justamente de uma perspectiva temporal; o impacto do pioneirismo na Arqueologia Brasileira. Quando o impacto é visto de forma estendida ou distendida, se percebe a ocorrência de dois expoentes que se tornaram fenômenos na Arqueologia Brasileira. Esses, ao logo do tempo e considerando seu contexto, assumiram determinadas linhas de pensamento, ratificando valores, saberes e certezas que, muitas vezes, mesmo não sendo posturas iniciais acabaram por serem enquadradas, pluralizando a perspectiva de um mundo real.

Esse mundo é permeado por significações para quem o reconhece como tal. Ele é pautado em códigos, conceitos e metodologias da prática científica arqueológica. Esses fenômenos científicos são reconhecidos por aqueles que o citam e mesmo quando o negam, posto que como numa fórmula matemática, ou melhor, no reconhecimento dessas Escolas encontram-se inúmeros denominadores comuns.

O entendimento, então, é que o conjunto de significados específicos é intertextual, portanto esse trabalho não está apenas na fala, ou nos objetos, mas, sobretudo, está na escrita. É justamente quando o passado passa a ser escrito, ou seja, se transforma num texto, estabelecendo um diálogo constante entre seu autor e sua audiência desconhecida e também, fundando-se em regras de múltiplas significações, conotações e implicações.

As palavras, todavia, não são tudo. $\mathrm{Na}$ verdade, é o contrário: elas nada são, ou antes, um "quase nada". Como um ácido, elas atacam (e esculpem?) o dado imediato do imaginário. (...) É verdade que, filosófica, poética, teológica, ou nascida de uma "sabedoria" popular que não possui todos esses belos títulos, a fala não faz desaparecer, por um ato mágico ao ser pronunciada, a imensa exibição das possessões que se oferecem à vista. Ela própria esta presa nesse elemento de onde sai e do qual se alimenta. Mas o único fato de falar restaura a ausência, proíbe a identificação com o imaginário e, sob a forma de um não, permite um movimento que pode ser o do sentido. (CERTEAU, 1995, p 51)

Ora, na sintaxe das palavras, do mundo ao qual nos referimos, onde exatamente estaria o sentido ou o significado cuja ocorrência fizesse com que lessem essas arqueólogas como expoentes dessas Escolas? Pois em nenhum dos textos assinados pelas autoras em questão se faz qualquer tipo de referência a Escolas...

Eis nossa problemática... O sentido... O sentido que se quer, o sentido que se tem ou o sentido que se cria... 
O universo do discurso se dá justamente na transferência das palavras. O que se quer dizer quando se afirma que Betty Jane Meggers é a Escola Americana e o que se quer dizer que Annette Laming-Emperaire é a Escola Francesa? A questão parece simples de resolver: que as duas são expoentes das respectivas Escolas.. A partir dessa interpretação é possível deslocar esse sentido para o que se quer buscar ao fazer essa análise; como e por que se deu a transformação das duas pesquisadoras em Escolas? A partir de que parâmetros as mesmas são vistas como Escolas?

Se, somente se, encontram-se sentidos semelhantes entre as Escolas e as arqueólogas, se tanto as Escolas quanto as arqueólogas são equivalentes, há transposição de sentido, portanto, se tem a ideia de movimento. Ricoeur (1983) afirma que toda metáfora é também definida em termos de movimento. Assim, a reflexão do discurso aqui presente torna-se também a análise desse movimento.

Um interesse pelo próprio movimento de transposição. Um interesse pelos processos, mais que pelas classes. Esse interesse poderá ser assim formulado: o que é que significa transpor o sentido das palavras? (RICOEUR, 1983, 27).

Ora, seria fácil de resolver o problema ao se voltar para o arqueólogo-mágico na intenção de verificarmos o que suas palavras tencionam dizer. A questão não é tão fácil de dirimir...

Segundo Ricoeur (1983), tudo o que possa ser dito das palavras resulta da sua correspondência com as ideias. Assim, falar das ideias e das palavras é falar duas vezes das ideias em si mesmas.

As ideias são os objetos que o nosso espírito vê. Nesta visão direta, ordenam-se todas as distinções entre ideias: ideias complexas, simples (...), concretas individuais, gerais; o mesmo se pode dizer do modo como elasse ligam e se encadeiam umas nas outras no nosso espírito para formar aí múltiplas associações, conjuntos, ou grupos diversos (RICOEUR, 1983; 81).

A ideia enquanto pensamento implica levar em conta que este é expresso através das palavras. Nesse sentido, o pensamento e as palavras são objetos que se podem considerar idênticos.

A palavra junto a sua interpretação se torna dramática quando ganha vida inteligível. Quando passa a ser um texto cuja plenitude encerra em si mesmo, porém abrindo-se a uma infinidade de janelas cujas interpretações podem ser múltiplas.

O texto é um nas mãos do autor, mas muitos nas mãos de seu público. Ou seja, quando vai ao encontro de seus leitores. Uma única leitura é capaz de abrir um universo multidimensional. A leitura é capaz de nos transportar no tempo e espaço, e de uma cultura 
a outra. Três caracteres aqui são importantes no entendimento dessa máquina do tempo; o texto, o autor e seus leitores.

No contexto arqueológico esse autor tem a capacidade mágica de transformar "coisas" ou "objetos" em palavras. E as palavras quando verbalizadas tornam-se muitas vezes reverberações incontroláveis.

A palavra na arqueologia se move num terreno que a situa duplamente. Por um lado, alcança um lugar na extensão da cultura material e, por outro, é escritura realizada pelo sujeito que descreve, traduz e interpreta a cultura material de um mundo a ser conhecido (Marques, 2010: 25).

Se a perspectiva é entender como se construiu a compreensão de que as autoras em questão são expressões maiores de Escolas Teóricas é preciso ir atrás dos rastros em que se pode verificar essas reverberações que se tornaram tão fortes na historiografia arqueológica. O rastro as identifica como expoentes de Escolas Teóricas, mas em nenhum momento se verifica, de fato, a existência dessas Escolas enquanto linhas de pesquisa científica.

A lógica se torna problemática na reverberação, pois, "a questão aí é de compreender como é que, o erro é possível, isto é, como é possível dizer o que não se verifica, se falar significa sempre dizer alguma coisa" (RICOEUR, 1976).

O ponto de partida é conceber os textos como corpus importantíssimo das questões da fala e portador dessa mensagem. Assim, estes se tornam estrutura fundamental para se entender como se fundamenta a construção de significados em torno dessas duas arqueólogas.

É importante entender a mensagem como um "modelo Estrutural" na tentativa de decodificá-lo. Para tanto, toda mensagem encarada como estrutura ou sistema é individual nas mãos de seu autor, mas seu código passa a ser coletivo quando aberto ao público.

A mensagem e o código não pertencem ao tempo da mesma maneira. Uma mensagem é um evento temporal na sucessão de eventos que constituem a dimensão diacrônica do tempo, ao passo que o código está no tempo como um conjunto de elementos contemporâneos, isto é, como um sistema sincrônico. Uma mensagem é intencional; é intentada por alguém. O código é anônimo e não intentado. Neste sentido, é inconsciente, não no sentido em que os impulsos e tendências são inconscientes, (..), mas, no sentido de um inconsciente estrutural e cultural, não libidinal. (RICOEUR, 1976. p 15) 
Para tanto se começa do pressuposto que se tem uma mensagem: a leitura (interpretação) de que Betty J. Meggers é fundadora ou a matriz em si da Escola Americanista, concorrentemente, há o pressuposto de que Annette Laming-Emperaire é a representação da Escola Francesa.

Numa observação atenta de produção teórica da arqueologia, especialmente das que foram pioneiras, a partir dos anos 60 quando se tem a introdução de uma arqueologia acadêmica, depare-se com as Escolas Americana e Francesa, como referências em teoria e metodologia.

As duas Escolas são historicamente uma marca forte na Arqueologia brasileira como tema que causava polêmica a partir de discussão, debates e críticas.

Os acontecimentos da cena política, social e principalmente acadêmica da introdução da Arqueologia como disciplina universitária no Brasil afetaram diametralmente o modo como os arqueólogos brasileiros identificavam as Escolas Arqueológicas. Estas por sua vez fortemente marcadas e incorporadas a duas personagens importantes nesse enredo; Betty Jane Meggers e Annette Laming-Emperaire.

Meggers começa suas incursões à América do Sul a partir de 1948. Seu primeiro trabalho de campo no Brasil foi à boca do Amazonas com intuito de terminar a sua tese de doutorado (The Archaeological Sequence on Marajo Island, Brazil, with Special Referencetothe Marajoara Culture). Essa experiência foi o divisor de águas no campo profissional posto que a convenceu de que a Amazônia e sua pré-história eram um complexo diferente quando comparado aos processos locais e influências regionais e vizinhas (POPSON, 2003:26).

Mas foi a partir de 1961 que começou a se pensar em montar uma arqueologia orientada a formação no Brasil. As bases foram criadas finalmente em 1964 por incentivo de uma bolsa Fulbright, Meggers e Evans, passaram a ministrar vários cursos aos brasileiros que fossem interessados em Arqueologia (MEGGERS, 1992:22).

As early 1964, Clifford Evans and Betty Meggers had organized what they called, an intensive seminar teaching archeological theory, methodology, ceramic classification and interpretation" to twelve pupils from seven different Brazilian states (Evans 1967:7). Immediately after the seminar, Evans and Meggers spent the month of November 1964 traveling through eleven Brazilian states and visiting university presidents and museum directors. A naive positivism was at the heart of this archeological team outlook. (FUNARI, 1995: p. 240) 
Em 1965, em colaboração com o Museu Goeldi, o Smithsonian Institution patrocinou o PRONAPA: Programa Nacional de Pesquisas Arqueológicas. Os métodos de campo e os critérios analíticos empregados foram os de uma análise quantitativa da cerâmica.

Já Annette Laming Emperaire começou suas incursões pela América do Sul a partir de 1951. Essas incursões na sua maioria foram feitas a partir de "Missões Francesas", acordos de pesquisa entre instituições de pesquisa da América do Sul e França, e começaram a tomar parte no Brasil em 1955, quando o casal começou a trabalhar com sambaquis no sul do Brasil(LAVALLÉE, 1978: 224).

Alternando suas estadias entre um período de pesquisa no extremo sul e outro na França, Annette Laming-Emperaire realiza com o marido a partir de 1955 missões frequentes ao Brasil principalmente no sul, onde eles procuraram vários sambaquis no litoral de São Paulo e Paraná. Muito por conta da semelhança de grande parte da franja de sambaquis da costa atlântica da América do Sul, que tem fronteiras comuns com aqueles que estão nas margens da linha do extremo sul do Chile (Idem).

Em 1971, a arqueóloga implementou um extenso programa de pesquisa arqueológica na região de Lagoa Santa, Minas Gerais (seis sítios) área que ficou famosa pelas descobertas de crânios humanos associados à fauna fóssil (área anteriormente escavada pelo paleontólogo dinamarquês Peter Wilhelm Lund sem sequência estratigráfica pendente até então). Ela encontrou um abrigo rochoso no sítio IV, onde em 1974-1975 descobriu a maioria dos ossos do que foi chamado Hominídeo 1 do Lapa Vermelha IV, o mais antigo fóssil humano no Brasil, cerca de 11 mil anos de idade. Ao crânio foi dado o apelido de Luzia.

Segundo Barreto (2000), a arqueologia acadêmica no Brasil surge a partir da vinda de especialistas estrangeiros, a entrada da arqueologia nas universidades e programas de pesquisa tais como o PRONAPA e as missões arqueológicas francesas proporcionaram a formação de toda uma primeira geração de arqueólogos acadêmicos brasileiros, ainda hoje responsáveis pela direção de vários centros de pesquisa e ensino de arqueologia no país.

Trata-se de uma formação essencialmente prática, de técnicas de pesquisa de campo e de classificação de materiais arqueológicos em laboratório.

Um levantamento realizado em 1972 demonstra que a maior parte dos profissionais envolvidos em pesquisa arqueológica até então não tinha formação específica em arqueologia e vinha, sobretudo, das áreas de história ou história natural, biologia e geociências (MENDONÇA DE SOUZA 1972). Uma parcela muito pequena vinha das áreas 
de ciências sociais ou antropologia, explicando assim a ausência de um projeto teórico para a arqueologia nacional (BARRETO, 2000: 45).

Assim, um dos questionamentos que vem à tona da associação destas pesquisadoras às Escolas Arqueológicas é o fato de se ter uma redução numa relação das mesmas com os respectivos projetos. Esse arrefecimento ou a compartimentação de todo um trabalho (ao longo de suas carreiras) está ligado à problemática das Escolas Arqueológicas.

Problemática, já que sua percepção e deferência estão ligadas principalmente no que tange a sua contribuição a formação de arqueólogos no Brasil.

Nessas narratividades da prática discursiva, um mundo se abre com novas possibilidades de reflexão. Reflexão entre as diversas interpretações sobre as Escolas, Americana e Francesa.

Ao se tomar a premissa de que as duas arqueólogas são Escolas, metaforicamente falando, percebe-se na transposição de sentido um movimento, então, pode se fixar ao enunciado. Se há a transposição de sentido, há um enunciado no meio contextual que por sua vez também é portador de sentido.

Uma vez enunciado, o mesmo é completo e finito. As Escolas são um todo. Elas identificam algo ou alguma coisa; elas identificam um discurso. Ora nesses termos como nos afirma Ricoeur, as implicações metodológicas são consideráveis já que poderíamos alargar a análise do discurso ao seu conjunto de constituintes (RICOEUR, 1983: 106-108).

Então, se pode afirmar que o que pode ser identificado consequentemente será reidentificado. A instância do discurso é um acontecimento eminentemente repetível.

Uma teoria do discurso deve então contemplar dois aspectos fundamentais: a sua constante atualização, realizado temporalmente, e o sentido da mensagem, retido e compreendido. Estamos diante da dialética de Evento e Significação expressa no trabalho de compreensão do discurso em Ricouer (COSTA, 1995: 17).

Se todo o discurso se atualiza como evento, todo o discurso é compreendido como significação. Por significação ou sentido designo aqui o conteúdo proposicional, que justamente descrevi como síntese de duas funções: a identificação e a predicação. Não é o evento enquanto transitório que queremos compreender, mas sua significação - o entrelaçamento do nome e do verbo (...) enquanto dura (RICOEUR, 1976: 23).

Quem foi, o que foi, e como se dá o Evento dentro dessa dicotomia ArqueólogasEscolas? Como se daria a organização de um mundo que vai se abrir tendo como centro essa relação dicotômica estabelecida na Arqueologia Brasileira?

\begin{tabular}{l|l|l|l|l|l|l|}
\hline (C) Rev. Arqueologia Pública & Campinas, SP & v.9 & N.1(11) $^{\circ}$ & p.18-35 & Jan-Jun/2015 & ISSN 2237-8294 \\
\hline
\end{tabular}


Dessa forma, afirma-se a existência de um Evento na Arqueologia Brasileira cuja temporalidade é permanentemente atualizada: as duas resguardando-se o seu contexto e seus textos são lidas como Escolas teóricas e metodológicas (por parte da historiografia arqueológica Brasileira).

Ao se voltar para os "Eventos", percebemos que as autoras em questão são vistas no presente enquanto discurso que as identifica como Escolas Arqueológicas. Simplificando: há um auditório que as identifica como correntes de postulados teóricos específicos. Se há um mundo partilhado e que lê as autoras como teóricas dessas Escolas, seria possível traçar os sinais cuja interpretação traria algum discernimento sobre o jogo de perguntas e repostas estabelecido na leitura destas como Escolas Teóricas? Se sim, então será possível estabelecer um diálogo com o intuito de discernir as mensagens para que se tenha a efetuação do discurso em si.

Nessa corrente, há um deslocamento de interesse: não só se prender às explicações obtidas ao longo de suas vidas e suas obras, mas como estas foram absorvidas e interpretadas e reinterpretadas ao longo do tempo. Então se tem outro caminho no qual se pode verificar a efetuação da linguagem quando discurso; o que se diz sobre elas.

$\mathrm{Na}$ relação texto/mensagem e leitor/código é importante perceber como também se dá a significação, pois faz parte do reconhecimento das duas nas vertentes de Eventos. Há um auditório particular que as reconheceu (e reconhece) como Escolas, muito por seu pioneirismo, mas sem dúvida pela extensão e complexidade de seus temas. Dessa forma, volta-se não só para os registros escritos, mas para a própria realidade social que as duas significaram para a comunidade arqueológica e acadêmica que deve ser considerada como elemento importante na pesquisa.

Têm-se uma realidade comum, partilhada, que necessariamente não pode ser transferida ao autor e no qual o leitor tem responsabilidade, esta realidade não pode ser fundamentada na sugestão ou insinuação. É preciso tomar cuidado com essa problemática posto que a referência e a representação são temas complexos.

Enfatizando a natureza "eventualista" do discurso das "Escolas" e de seu lugar na Arqueologia Brasileira, há um destaque para as possibilidades que estes representam no presente quando vistos sob o prisma de sua voz (como também o fato dos mesmos possibilitarem vozes autorais). Essa perspectiva chama atenção não só para o autor, mas para a dialética que ele estabelece com outros autores que o usam como base.

Quando se afirma as Escolas através de uma discursividade consubstanciada qual Evento na Arqueologia Brasileira se percebe um sistema que é virtual e fora do tempo. Sendo assim, o surgimento do discurso qual Evento, a "instância do discurso", é o fato de 
ele ser sempre performático. O que por sua vez irá nos remeter a "quem fala", a quem pronuncia o discurso.

As Escolas não podem ser separadas das interpretações através das quais elas chegaram até nós. Se quisermos de alguma forma alcançá-las em toda sua extensão é preciso tentar alcançar essas interpretações. Não se pode despi-las da história que carregam e que se fazem presentes no hoje, no agora. Entender as Escolas Arqueológicas significa entender sua história essencial.

A reconstrução das circunstâncias originais, como toda restauração do tipo, consiste numa realização sem sentido, tendo em vista a historicidade de nosso ser. O que é reconstruído, uma vida trazida do passado perdido, não é a original. Em sua continuação num estado alienado, ela adquire comumente uma existência cultural secundária. Mesmo a pintura retirada do museu e recolocada na igreja, ou uma construção restaurada à sua condição original já não são mais o que eram antes - tornam-se simplesmente atrações turísticas. De modo semelhante, uma hermenêutica que considera o entendimento como a reconstrução do original não seria mais que a recuperação de um significado morto (GADAMER, 2008: 245).

Ora, não se pode conceber um Evento, no caso, as Escolas, como uma estrutura, congelada e a espera de uma tradição interpretativa que possa dar conta da verdadeira experiência, abordagem ou intencionalidade inerente ao mesmo. É preciso dar conta que as Escolas, como um "todo coerente" quando é atirado ao público é metaforicamente como algo atirado ao rio: nunca refaz o mesmo caminho, ao imergir num fluxo de águas que resistem a um domínio.

Aos complexos textuais somamos suas referências históricas originais, e suas referências históricas (textuais) contemporâneas. E, quanto às críticas, aos preconceitos historicamente condicionados, é possível encará-los como obstáculos ao entendimento, porém estes são de fundamental importância ao entendimento das múltiplas interpretações gradualmente acumuladas e acondicionadas ao Evento que se tornaram as Escolas Arqueológicas Brasileiras.

Por isso o esforço deve ser antes de tudo entender "como se deu a construção de significados" e não "recuperar determinados significados". A atitude é de reflexão (sem deixar de historicizar as problemáticas), mas, sobretudo compreender, tendo os textos das autoras como fontes primárias, acrescidos da fala e dos textos, do que se diz sobre as mesmas, como fontes secundárias e de aporte a fim de se chegar ao paradigma fundamental e do qual eles são nossas principais testemunhas. Para através de seus sinais 
(sua significação) encontrar o mundo partilhado, sendo possível assim, se questionar que mundo é esse...

Não há eventos que ocorram sem a presença de objetos, ou entidades. Evento é o diferencial: o evento ocorre num dado lugar e num dado espaço; os fatos por ele gerados permanecem no tempo e no espaço.

O que seria realmente relevante na prática arqueológica que pudesse alavancar um trabalho ao posto de corrente ou postulado teórico?

O que significa produzir teoria na Arqueologia brasileira? Significa adotar posturas e concepções teóricas externas? No campo teórico da Arqueologia, há muitas possibilidades de escolha, categorizações e interpretações.

A teoria é totalmente subjetiva. Ela não é um produto técnico qualquer de um especialista, mas uma produção definida e localizada resultante de uma interação específica e contextualizada entre os indivíduos e as experiências que esses indivíduos trazem, e a forma como eles interagem em suas vidas e em seu trabalho, e como os arqueólogos a constroem para chegar a ter uma imagem do passado com base nos restos de material contingente. (SHANKS E TILLEY, 1987: 212-213)

$\mathrm{Na}$ busca de respostas, talvez certo fosse posicionar outra questão subjacente: $\mathrm{O}$ que seria imprescindível na Arqueologia ao fazer a distinção do que é senso comum, e do que é realmente uma explicação científica? Que argumentos poderiam, de uma maneira geral, ser comprovados e objetivados como confirmações empíricas no campo pertencentes a determinadas linhas de pesquisa? Quais seriam os critérios de verdade, as práticas essências ao se tomar como pertencentes a uma determinada teoria na Arqueologia sulamericana?

Ao encontrar respostas para essas questões vai se saber delinear quais foram os paradigmas estabelecidos através das normas e regras ditadas por essas "Escolas", e que regem de alguma forma às condutas daqueles que as praticam em campo, como operações e princípios válidos para se desenterrar e documentar a cultura material.

Para tanto, é preciso nos dirigir aos alicerces do edifício conceitual, imagético e político que nos remetem a essas Escolas. Nesse campo de investigação torna-se imprescindível voltar às circunstâncias históricas e todas as suas possíveis implicações.

Como se deu ao longo desse percurso a metodologia por elas empregada? Quais seus problemas epistemológicos, surgidos das elucubrações teóricas e também das problemáticas de campo? Como as mesmas se inserem, ou podem ser inseridas dentro do contexto por elas vivenciado na esfera do político, do social e cultural brasileiro? 
A reflexão, assim, direciona-se há um conjunto de fenômenos que possivelmente podem ser definidos como uma teoria ou teorias explicativas particulares cuja metodologia é reconhecida como Escola. Por sua vez o conjunto "teoria + metodologia" daria lugar a modelos que por sua vez estão intrinsecamente relacionados a essas pesquisadoras e com seus trabalhos arqueológicos.

A noção de influência também pode criar um paradigma que seria compartilhado através da enumeração de pressupostos comuns, questões, temas, ou argumentos. Segundo La Capra (1983), se faz necessário também elucidar como os empréstimos ou os pontos em comum funcionam de fato no texto. Ou seja, como as ideias comuns operam diferentemente em distintos textos ou obras instituintes de uma dada "comunidade".

$\mathrm{Na}$ visualização desse Evento, outra perspectiva é a característica de ambas as trajetórias marcadas pelo pioneirismo na Arqueologia Brasileira. As pesquisadoras fazem parte de uma parcela de arqueólogos que teve sua trajetória marcada por pesquisas pioneiras nas terras da América do Sul. No caso, elas foram pioneiras não só porque aqui a arqueologia acadêmica era muito incipiente, mas também ao desbravar o território (sítios descobertos) e a pesquisa na América do Sul.

Em seu pioneirismo, pode-se enfatizar a transmissão de seus conhecimentos sociais, a fim de investigar se esse exercício nos trará a perspectiva de uma das unidades do Evento.

Já em sua retórica, ao tratar de temas globalizantes, inserindo a América na Préhistória mundial, há também possibilidade das mesmas terem sido vistas qual Eventos e, portanto, ao longo do tempo se deu a associação e leitura destas pesquisadoras como Escolas. O que representou a tomada de lugar na medida em que a voz e o poder dessas arqueólogas na América do Sul passavam a se fazer ouvir (esse continente transforma-se num grande sítio arqueológico conduzido pelo trabalho de Meggers ou de Emperaire)?

$\mathrm{Na}$ narrativa que as duas construíram ao longo de sua carreira, são perceptíveis dois caminhos diferentes (duas vertentes) que perpassam a Pré-história Sul-americana. Vale a pena visitar esses caminhos por estarem relacionados aos objetivos que as duas pesquisadoras tinham antes de vir desbravar essas terras: "Des-cobrir" como se deu a entrada do homem no continente Americano! Pergunta-se: Existe uma representatividade das mesmas para a comunidade científica? Que tipo de representatividade é essa? Qual a importância dessa representatividade ao se ler as duas como Escolas teóricas?

Já que o Evento é sempre uma performance de constante atualização a partir de nossa competência linguística, as Escolas não deixam de serem performáticas 
desenvolvidas como modelo discursivo que se refere aos seus locutores (quem fala é quem cria), criando assim um mundo próprio, atemporal e permeado de subjetividades.

Des-cobrir esse mundo é estabelecer um diálogo, no entendimento deste Evento para se entender ou mensurar sua significação. E se há a efetuação destas em correspondência a Eventos que enfim se possa compreender seu programa e conteúdo como um conjunto de significados dentro de um corpo teórico e metodológico reconhecido numa atitude de abertura a um "mundo discursivo", sem esquecer-se de nossos posicionamentos críticos perante tal.

\section{Por um ponto final?}

"E, eu, que já fui uma brasa. Se assoprarem posso acender de novo!"(Adoniran Barbosa)

Seria possível esquecer os ecos que adjetivam essas "Escolas" e suas "fundadoras"?

Existe, entretanto, uma diferença muito grande entre aquele tipo elementar de trabalho e a leitura crítica e interpretativa de documentos históricos, principalmente quando destinados à construção de um discurso teoricamente orientado, em uma monografia histórica de qualidade. Neste caso, não basta saber explicar o documento, mas torna-se fundamental expor claramente 0 conjunto de conhecimentos que nele se expressa, a partir de um sólido juízo crítico embasado, sobretudo na razão (KERN, 2001: 9).

O processo de reconhecimento dessas "Escolas" ainda não atingiu um estágio de equilíbrio suficiente em que se pode afirmar sem se contestar, ou afirmar sem acusar. Afinal, podemos reconhecer nossos discursos em cima de todo um trabalho sem menosprezá-lo ou atacá-lo? Trata-se de buscar um ponto de equilíbrio.

Des-cobrir seria o ato de divulgar aquilo que é conhecido, porém, não entendido. Resolver no sentido de procurar um entendimento que possa desdobrar as Escolas num prisma cuja coerência pretende se distanciar de um discurso fechado, e de julgamentos e interpretações redutivas.

Será possível a adoção de uma perspectiva histórica em que se possa dar conta de uma construção social, acadêmica e de certa forma política que ganhou força num mundo partilhado? Se há uma cadeia de reprodução desse mundo é possível romper com a 
mesma, ou será melhor manter sua legitimidade a partir de categorias próprias de percepção?

Decerto é que a mudança se faz necessária! A mudança no olhar não só referente à "como" compreende-se (se há compreensão) as Escolas, mas como em determinados momentos a Arqueologia produziu e reproduziu estas Escolas. A historiografia em questão pode considerar olhar para estas Escolas sob um aspecto particular; rever as discussões que estas pesquisadoras suscitam.

Podemos muitas e muitas vezes descongelar este passado interpretando-o a partir de um novo viés. Resignificando um discurso estático e hermeticamente acondicionado. Assim, esses discursos podem servir de trampolim para se ultrapassar barreiras invisíveis impostas por nossa própria acomodação. O objeto desse passado vai se tornar vivo e latente, e fará justiça ao trabalho dessas pesquisadoras. Bem como poderá se transformar em múltiplas vozes, múltiplas interpretações, enfim outras verdades, se não uma, aí sim se terá um salto científico.

As letras aqui reunidas marcam certos passos de um percurso que corresponde a duas décadas de investigação e trabalho associados à trajetória de duas vidas, de duas arqueólogas, de duas pesquisadoras. Esse percurso tem intuito de reagir, ora ao silêncio, ora ao barulho, que as duas (ou melhor, pelas questões evocadas por elas) causam no meio arqueológico. Elas são, ou foram brasas...

Por méritos próprios, essas duas arqueólogas, tornam-se, em determinado momento, o que há de melhor, na arqueologia brasileira; a brasa incandescente que sai do fogo totalitário. Reconhecidas nessas chamas abrasivas, elas fazem parte desse continuum... Mas apagadas, conforme alijadas desse mesmo fogo...

O fogo pode e deve ser sempre alimentado, quem dá o sopro somos nós... Esse sopro também pode e deve correr em múltiplas direções.

\section{Referencias Bibliográficas}

BARRETO, C. A Construção De Um Passado Pré-Colonial: Uma Breve História Da Arqueologia No Brasil. Revista USP, São Paulo, n.44, p. 32-51, dezembro/fevereiro 19992000.

COSTA, M. S. D. Sobre a teoria da interpretação de Paul Ricoeur. Porto: Ed. Contraponto, 1995.

DE CERTEAU, M. A. Cultura no plural. Campinas: Papirus, 1995.

FUNARI, P. P. A. Theory in Archaeology, a world perspective. London: Routledge, 1995.

\begin{tabular}{|l|c|c|c|c|c|c|} 
(C) Rev. Arqueologia Pública & Campinas, SP & v.9 & N $^{\circ} .1(11)$ & p.18-35 & Jan-Jun/2015 & ISSN 2237-8294
\end{tabular}


GADAMER, H. G.Verdade e Método. V.1 e 2, Petrópolis: Vozes, 2008.

HODDER, I. Agency in archaeology. New York and London: Routledge, 2000.

JORGE, V. O. Projectar o Passado. Ensaios sobre Arqueologia e Pré-história. Lisboa, Ed. Presença, 1987.

KERN, A. A. Os textos teóricos sobre a História: análise crítica e interpretações. Histórica: Revista da Associação dos Pós-Graduandos em História. Porto Alegre: APHG, PUCRS, n. 5, pp. 09-20, 2001.

LAMING-EMPERAIRE. A. Missions archéologiques françaises au Chili Austral et au Brésil Méridional. Journal de la Société des Américanistes, 1968, persee.fr, Acesso em: 28 de Julho de 2012.

LAVALLÉE, D. Annette Laming-Emperaire (1917-1977). Journal de la Société des Américanistes, Paris, Volume 65, 1978: p. 224-226.

LIMA, L. C. Mímesis e modernidade: formas das sombras. Rio de Janeiro: Edições Graal, 1980.

MARQUES, M., Pedra que te quero palavra: discursividade e semiose no (con)texto arqueológico da Tradição Itaparica. Porto Alegre: PUCRS, tese de doutorado, 2010.

MEGGERS, B. J. Prehistoria sudamericana; nuevas perspectivas. Washington: Taraxacum, 1992.

MORIN, E. Ciência com consciência. Rio de Janeiro: Bertrand Brasil; 2003.

PEDROSA, T. Arqueologia e interpretação: a criação de dois modelos arqueológicos para a Amazônia. - Porto Alegre, Dissertação (Mestrado em História) - Faculdade de Filosofia e Ciências Humanas, PUCRS, 2008.

E eu, que já fui uma brasa, se assoprarem posso acender de novo: arqueologia enquanto evento na trajetória de duas pioneiras. Tese de Doutorado, PUCRS, 2012.

PIRIE, A. Constructing prehistory: Lithic analysis in the Levantine Epipalaeolithic. Journal of the Royal Anthropological Institute, 2004 - Wiley Online Library.

POPSON, C. P. First Lady of Amazonia. Archaeology, London, Volume 56 Number 3, p 26, May/June 2003.

PRONAPA. An Interim Report on the National Program of Archeology Research. Antiquity, 35 (1), 1-23; Chicago; 1970.

RICOEUR, P. A metáfora viva. São Paulo: Edições Loyola, 1983.

Teoria da Interpretação. Lisboa: Edições 70, 1976.

SHANKS E TILLEY. Social Theory and Archaeology. Oxford, Polity press, 1987.

\begin{tabular}{|l|c|c|c|c|c|c|}
\hline (C) Rev. Arqueologia Pública & Campinas, SP & v.9 & N $^{\circ} .1(11)$ & p.18-35 & Jan-Jun/2015 & ISSN 2237-8294
\end{tabular}


TILLEY, C. Meta archaeology project - On modernity and Archaeological Disccourse. Fragmento disponível em: < http://archaeology.kiev.ua/meta/tilley.html> Acesso em $18 / 07 / 2012$.

TILLEY. C. Metaphor and material culture. New York, Wiley-Blackwel,1999. 